\title{
Mobil Robotların Yol Planlamasında Doğrusallığın İncelenmesi
}

\author{
Mustafa Yusuf Yıldırım ${ }^{1 *}$, Rüştü Akay² \\ 1*Erciyes Üniversitesi, Mühendislik Fakültesi, Mekatronik Mühendisliği Bölümü, Kayseri, Türkiye, (ORCID: 0000-0003-0302-8466), myyildirim@erciyes.edu.tr \\ ${ }^{2}$ Erciyes Üniversitesi, Mühendislik Fakültesi, Mekatronik Mühendisliği Bölümü, Kayseri, Türkiye (ORCID: 0000-0002-3585-3332), akay@erciyes.edu.tr
}

(2nd International Conference on Access to Recent Advances in Engineering and Digitalization (ARACONF)-10-12 March 2021)

(DOI: 10.31590/ejosat.902932)

ATIF/REFERENCE: Yıldırım, M. Y., Akay, R. (2021). Mobil Robotların Yol Planlamasında Doğrusallığın İncelenmesi. Avrupa Bilim ve Teknoloji Dergisi, (24), 138-142.

$\ddot{O} \mathbf{z}$

Endüstriyel ortamlarda giderek daha fazla kullanılan mobil robotlar için yol planlanması önemli bir problemdir. Bu problem, engelli bir ortamda başlangıç düğümünden hedef düğüme kadar mesafe ve süre gibi bazı kriterler dikkate alınarak engellere çarpmadan uygun bir yolun bulunmasıdır. Alternatif yolların üretilmesinde doğrusal (düz çizgi) veya doğrusal olmayan (eğri) amaç fonksiyonlarının kullanılması performansı önemli ölçüde etkilemektedir. Bu çalışmada, küresel yol planlama için farklı zorluk derecelerine sahip ortamlarda doğrusal ve doğrusal olmayan amaç fonksiyonlarının kullanımı karşılaş̧ırmalı incelenmiştir. Uygun yolların bulunmasında evrimsel algoritmalardan biri olan genetik algoritma (Genetic Algorithm, GA) kullanılmıştır. Simülasyon sonuçları, mobil robotların yol planlamasında doğrusal amaç fonksiyonu kullanılmasının hem mesafe hem de algoritma çalışma süresi açısından avantajlı olduğunu göstermiştir.

Anahtar Kelimeler: Mobil Robot, Yol Planlama, Optimizasyon, Genetik Algoritma, Yol Doğrusallığı.

\section{Investigation of Linearity in Path Planning of Mobile Robot}

\begin{abstract}
Path planning is an important problem for mobile robots, which are increasingly used in industrial environments. This problem is to find a suitable path from a starting node to a target node without colliding obstacles, taking into account some criteria such as distance and time. The use of linear (straight line) or nonlinear (curve) objective functions in the generation of alternative paths significantly affects the performance. In this study, the use of linear and nonlinear objective functions for global path planning in environments with different degrees of difficulty has been comparatively examined. Genetic algorithm (GA), one of the evolutionary algorithms, was used to find suitable paths. The simulation results showed that using the linear objective function in path planning of mobile robots is advantageous in terms of both distance and algorithm running time.
\end{abstract}

Keywords: Mobile Robot, Path Planning, Optimization, Genetic Algorithm, Path Linearity.

\footnotetext{
*Sorumlu Yazar: myyildirim@erciyes.edu.tr
} 


\section{Giriş}

Günümüzde mobil robotların yük taşımacılığından arama kurtarma, madencilik ve savunma sanayiye kadar birçok sektörde uygulama alanı mevcuttur ve gün geçtikçe kullanımı artmaktadır (Ajeil vd., 2020). Bu robotlara verilen görevlerden biri de yol planlama olarak adlandırılan belirlenen bir hedefe optimum maliyetlerle ulaşmasıdır. $\mathrm{Bu}$ hedefe engellere çarpmadan kabul edilebilir sürelerde ulaşması beklenir (Song vd., 2021). Yol planlamada klasik (hücre ayrıştırma, yapay potansiyel alan, hızlı-keşfedilen rastgele ağaçlar vb.) (Liu vd., 2019, Contreras-Cruz vd., 2015) ve evrimsel hesaplamalara dayalı (genetik algoritma, diferansiyel gelişim algoritması vb.) (Saicharan vd., 2017) çok sayıda yaklaşım bulunmaktadır. Özellikle evrimsel algoritmaların hesaplama açısından daha verimli olması sebebiyle kullanımları her geçen gün daha da artmaktadır ve en büyük avantajlarından biri amaç fonksiyonlarının gradyanlarını hesaplamalarına ihtiyaç duymamalarıdır (Ergezer \& Leblebicioğlu, 2011). Bu amaç fonksiyonları yolun uzunluğu, güvenliği, robotun enerjisi gibi kriterlerle oluşturulmaktadır. Ancak bu kriterler kadar yolun doğrusallığı da ön planda tutulmalıdır. Dolayısıyla yol planlamada doğrusal ve doğrusal olmayan amaç fonksiyonları da oluşturulabilir. Her iki amaç fonksiyonu da engellere çarpmadan yolun uzunluğunu minimize etmektedir. Ancak doğrusal amaç fonksiyonu yolun bölmelerini düz çizgi şeklinde doğru uydurma yöntemiyle oluştururken, doğrusal olmayan amaç fonksiyonu yolun bölmelerini eğri şeklinde eğri uydurma gibi yöntemlerle oluşturmaktadır.

Literatürde evrimsel algoritmaların kullanıldığı yol planlama çalışmalarından bazıları doğrusal ve doğrusal olmayan amaç fonksiyonlarının kullanıldığı kategorilerde incelenmiştir. Doğrusal olmayan amaç fonksiyonunun kullanıldığ çalışmalardan; Yu vd. doğal afet durumlarında arama - kurtarma görevi için bir insansız hava aracının üç boyutlu yol planlamasında geliştirilmiş bir diferansiyel gelişim (Differential Evolution, DE) algoritması önermişlerdir (Yu vd., 2020). Yu vd. başka bir çalışmasında arama - kurtarma görevi için Bezier teorisi tabanlı farklı bir DE algoritması önermişlerdir (Yu vd., 2021). Niu vd. okyanus görevleri için bir insansız yüzey aracına yönelik bir yol planlama yöntemi önermişlerdir. $\mathrm{Bu}$ yöntem voronoi yol haritası, dijkstra algoritması, kıyı şeridi genişletme (Coastline Expanding) ve GA tabanlıdır (Niu vd., 2020). Orozco-Rosas vd. yol planlama problemi için GA ve yapay potansiyel alan yöntemini birleştiren yeni bir yöntem önermişlerdir (Orozco-Rosas vd., 2019). MahmoudZadeh vd. otonom bir su altı aracı için parçacık sürüsü optimizasyonu (Particle Swarm Optimization), biyocoğrafya tabanl optimizasyon (Biogeography-Based Optimization), DE ve ateşböceği algoritması (Firefly Algorithm) bir arada kullanıldığı bir yol planlama yöntemi önermişlerdir (MahmoudZadeh vd., 2018). Doğrusal amaç fonksiyonunun kullanıldığ 1 çalışmalardan; Cai vd. antikor çeşitliliğinin korunduğu bağışıklık evrim algoritmasının (Immune Evolution Algorithm) kullanıldığı bir yol planlama yöntemi önermişlerdir (Cai vd., 2008).

Genetik algoritma, evrimsel algoritmaların en temel ve popüler algoritmalarından biridir ve mobil robotların yol planlama probleminde kullanıldığı çok sayıda çalışma mevcuttur (Davoodi vd., 2015). Bu çalışmaların da bazıları doğrusal ve doğrusal olmayan amaç fonksiyonlarının kullanıldığ kategorilerde incelenmiştir. Doğrusal olmayan amaç fonksiyonunun kullanıldığı çalışmalardan; Elhoseny vd. çözümlerin çeşitliliğini artıran geliştirilmiş bir GA kullanan Bezier eğrisi tabanlı bir yol planlama yöntemi önermişlerdir (Elhoseny vd., 2018). Patle vd. Sylvester Atalet Yasas1 (Sylvester Law of Inertia) ve ikili kod kullanan geliştirilmiş bir GA'dan oluşan bir yol planlama yöntemi önermişlerdir (Patle vd., 2018). Raja vd. engebeli arazide hareket eden bir mobil robot için geliştirilmiş bir potansiyel alan yöntemi ve genetik algoritmayı birleştiren bir yol planlama yöntemi önermişlerdir (Raja vd., 2015). Bakdi vd. deneysel çalışma olarak bir iç mekân mobil robot için bir yol planlama yöntemi önermişlerdir. $\mathrm{Bu}$ yöntemde optimum yollar GA ile planlanmış, optimum yolu yumuşatmak için parçalı kübik hermite interpolasyon polinomu (Piecewise Cubic Hermite Interpolating Polynomial) kullanılmış ve robotun izlenmesi için bir uyarlanabilir bulanık mantık denetleyicisi (Adaptive Fuzzy-Logic Controller) tasarlanmıştır (Bakdi vd., 2017). Mohanta vd. birden fazla hedefi olan çoklu bir mobil robot sisteminin yol planlaması için GA'nın kullanıldığı bir yöntem önermişlerdir. Bu yöntemde navigasyon kontrolü için GA'yı Petri-Net modeline dâhil etmişlerdir (Mohanta vd., 2011). Doğrusal amaç fonksiyonunun kullanıldığ çalışmalardan; Qu vd. çoklu bir mobil robot sistemi için birlikte evrim mekanizmasını (Co-Evolution Mechanism) içeren bir GA önermişlerdir (Qu vd., 2013). Sarkar vd. birden fazla hedef noktası olan bir mobil robot için, dört farklı operatörün dâhil edildiği bir GA önermişlerdir (Sarkar vd., 2020). Tuncer vd. dinamik ortamlarda hareket eden bir mobil robotun yol planlaması için yeni bir mutasyon operatörünün dâhil edildiği geliştirilmiş bir GA önermişlerdir (Tuncer \& Yildirim, 2012).

Literatürdeki çalışmalar incelendiğinde yol planlama problemlerinin çoğunun doğrusal olmayan amaç fonksiyonları ile modellendiği gözlemlenmiştir. Ayrıca aynı çalışma içerisinde farklı amaç fonksiyonlarının etkilerinin incelendiği bir çalışmaya rastlanmamıştır. $\mathrm{Bu}$ sebeple bu çalışmada, mobil robotlar için yol planlamada doğrusal ve doğrusal olmayan yaklaşımların en kısa mesafe ve çalışma süresi açısından incelenmesi amaçlanmıştır.

Çalışmanın bölümlerini şu şekilde sıralamak mümkündür: İkinci bölümde materyal ve yönteme, üçüncü bölümde bulgulara, dördüncü bölümde de sonuca yer verilmiştir.

\section{Materyal ve Metot}

\subsection{Amaç Fonksiyonları}

İnceleme için doğrusal ve doğrusal olmayan iki amaç fonksiyonu oluşturulmuştur. İki amaç fonksiyonunun da temeli aynıdır ve iki kısımdan oluşmaktadır. Birinci kısım robotun gideceği yolun uzunluğunu hesaplarken, ikinci kısım da robot ile engeller arasındaki uygulanabilir mesafeyi (engelden kaçınma kontrolü) hesaplar. Bu fonksiyon Eşitlik 1'de gösterilmektedir.

$\min F\left(P_{i}, O_{j}\right)=L\left(P_{i}\right) \cdot\left[1+\beta \cdot V\left(P_{i}, O_{j}\right)\right], i=1, \ldots, d ; j=1, \ldots, o$

Burada $F\left(P_{i}, O_{j}\right)$ minimize edilecek temel fonksiyon, $P_{i}$ yol için oluşturulan nokta dizisinde i. noktanın konumu, $\mathrm{O}_{\mathrm{j}} \mathrm{j}$. engelin konumu, $\mathrm{L}\left(\mathrm{P}_{\mathrm{i}}\right)$ yol uzunluk denklemi, $\beta$ engelden kaçınma faktörü, $V\left(P_{i}, O_{j}\right)$ engelden kaçınma kontrol denklemi, d nokta dizisinin boyutu (nokta sayısı) ve o engel sayısıdır. Yol uzunluk denklemi Eşitlik 2'de gösterilmektedir. 
$\mathrm{L}\left(\mathrm{P}_{\mathrm{i}}\right)=\sum_{\mathrm{i}=1}^{\mathrm{d}-1} \sqrt{\left(\mathrm{P}_{\mathrm{ix}}-\mathrm{P}_{(\mathrm{i}+1) \mathrm{x}}\right)^{2}+\left(\mathrm{P}_{\mathrm{iy}}-\mathrm{P}_{(\mathrm{i}+1) \mathrm{y}}\right)^{2}}$

Burada $\mathrm{P}_{\mathrm{ix}}$ ve $\mathrm{P}_{\mathrm{iy}}$ nokta dizisindeki i. noktanın konumu, $\mathrm{P}_{(\mathrm{i}+1) \mathrm{x}}$ ve $\mathrm{P}_{(\mathrm{i}+1) \mathrm{y}}$ nokta dizisinde $(\mathrm{i}+1)$. noktanın konumudur. Engelden kaçınma kontrol denklemi Eşitlik 3 'te gösterilmektedir. Engeller dairesel olarak tasarlanmışıtır ve burada $a_{i}$ engellerin yarıçapını temsil etmektedir (Chołodowicz \& Figurowski, 2017).

$\mathrm{V}\left(\mathrm{P}_{\mathrm{i}}, \mathrm{O}_{\mathrm{j}}\right)=\sum_{\mathrm{i}=1}^{\mathrm{o}}\left[\sum_{\mathrm{j}=1}^{\mathrm{d}} \max \left(1-\frac{\sqrt{\left(\mathrm{P}_{\mathrm{jx}}-\mathrm{O}_{\mathrm{ix}}\right)^{2}+\left(\mathrm{P}_{\mathrm{jy}}-\mathrm{O}_{\mathrm{iy}}\right)^{2}}}{\mathrm{a}_{\mathrm{i}}}\right)\right]$

Robotun takip edeceği yolun belirlenmesi için belli noktalara ihtiyaç duyulmaktadır. Çalışmada bu noktalara parametre noktaları adı verilmekte ve $\mathrm{n}$ notasyonu ile sembolize edilmektedir. İlk olarak her iki amaç fonksiyonuna da girdi olarak gelen bu parametre noktalarının konumları, planlanacak yolun başlangıç ve bitiş noktaları ile birlikte farklı satır vektörlerine aktarılmaktadır. Ancak doğrusal amaç fonksiyonunda bu vektörlere doğru uydurma (linear interpolation) uygulanarak nokta dizisi elde edilirken; doğrusal olmayan amaç fonksiyonunda bu dizi eğri uydurma (cubic spline interpolation) uygulanarak elde edilmektedir. Bu nokta dizileri ile oluşturulan yolların maliyetleri temel fonksiyonda aynı şekilde hesaplanmaktadır. Doğrusal ve doğrusal olmayan amaç fonksiyonlarının oluşturdukları yollara bir örnek Şekil 1'de gösterilmektedir.

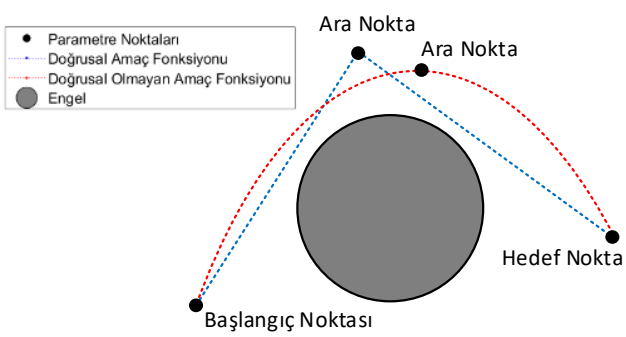

Şekil 1. Doğrusal ve Doğrusal Olmayan Amaç Fonksiyonlarının Oluşturdukları Yollara Birer Örnek

\subsection{Amaç Fonksiyonları}

Genetik algoritma, doğal seçilime dayanan bir evrimsel algoritmadır. İlk olarak 1960'ta Holland tarafindan geliştirilmiştir. Bu algoritmada temel olarak seçim, çaprazlama ve mutasyon adı verilen üç operatör bulunmaktadır. İlk popülasyon (kromozomlar) rastgele oluşturulmakta ve bunların uygunluk değerleri bir fonksiyon tarafindan değerlendirilmektedir. Seçim operatöründe, ebeveynler uygunluk değerlerine göre seçilmektedir. Çaprazlama operatöründe, rastgele bir sayı oluşturulmakta ve bu sayı çaprazlama oranından küçükse seçilen ebeveynler çaprazlanmaktadır, böylece yeni çözümler elde edilmektedir. Mutasyon operatöründe, bazı çözümlerin genetik yapısı bir mutasyon oranına göre değiştirilmekte, böylece popülasyondaki çeşitlilik artırılmaktadır. En iyi çözüm bellekte saklanmakta ve yinelemeli süreç durdurma kriteri sağlanana kadar devam etmektedir (Lamini vd., 2018). GA algoritmasının genel sözde kodu Algoritma 1'de gösterilmektedir.
Algoritma 1. GA algoritmasının genel sözde kodu (Lamini vd., 2018)

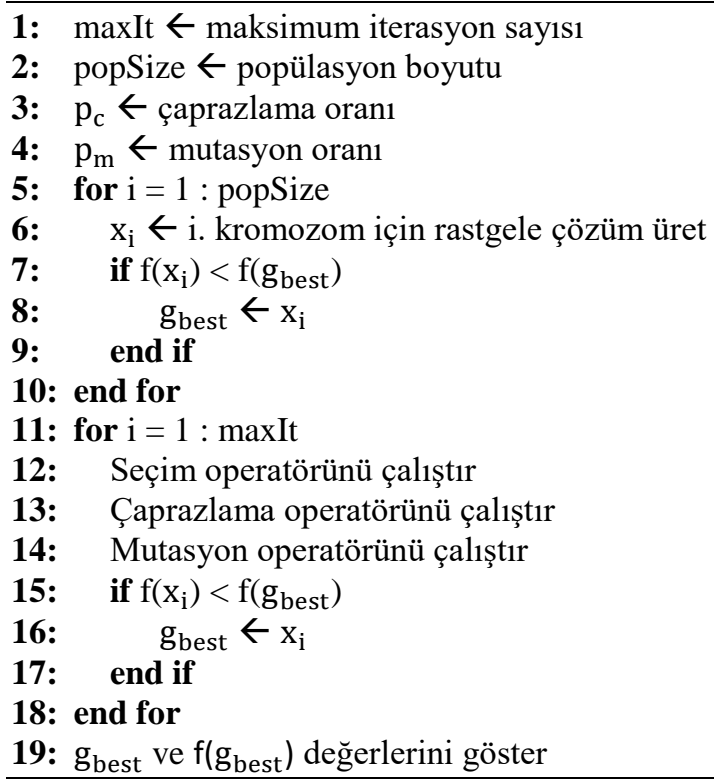

\section{Bulgular}

İnceleme MATLAB 2019 programlama dilinde kodlanarak gerçekleştirilmiştir. $\mathrm{Bu}$ inceleme için Windows 10 işletim sistemi, INTEL CORE i7 işlemcisi, 16 GB RAM'e sahip bir bilgisayar kullanılmıştır. Ortam, 10 x $10 \mathrm{~cm}$ boyutlu bir karesel alan olarak tasarlanmıştır. Robotun başlangıç konumu ortam ekranının sol alt köşesi, hedef konumu ise sağ üst köşedir. Engelsiz en kısa mesafe $14.142 \mathrm{~cm}$ 'dir. Engel ihlali faktörü ve nokta dizisinin boyutu 100 'dür. Her iki amaç fonksiyonu için parametre noktalarının sınır değerleri $\mathrm{x}$ ve y için $\left[\begin{array}{ll}0 & 10\end{array}\right]$ olarak belirlenmiştir. Bu çalışmada kullanılan iki ortam Şekil 2'de gösterilmektedir.

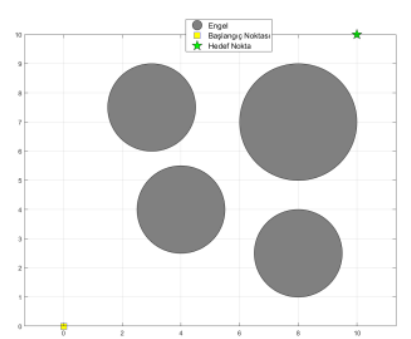

(a)

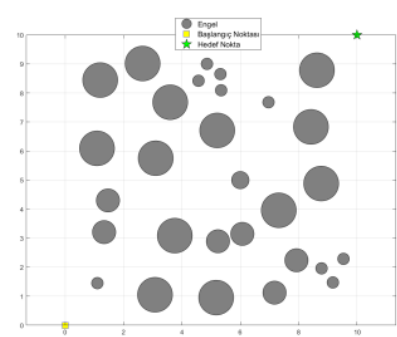

(b)
Şekil 2. Çallşmadaki ortamlar: (a) Ortam 1, (b) Ortam 2.

İnceleme için Heris (2020)'in geliştirdiği GA, kontrol parametreleri değiştirilmeden (çaprazlama oranı 1, mutasyon oranı 0,1) kullanılmış, sadece maksimum iterasyon sayısı 100 ve popülasyon boyutu 50 için çalıştırılmıştır. Problemin parametre sayısı (n) ortam 1 için 3, ortam 2 için 5 olarak belirlenmiştir. İnceleme sonucunda her iki ortam için elde edilen ortalama en kısa mesafeler, algoritmanın çalışma süreleri ve doğrusal fonksiyonun doğrusal olmayan fonksiyona göre azalma oranları Tablo 1'de, örnek bir çalışma için her iki ortamda elde edilen yollar Şekil 3 'te, ilgili örnek için yakınsama grafikleri Şekil 4 'te gösterilmektedir. 
Tablo 1. Her iki ortam için elde edilen ortalama en kısa mesafeler, algoritmanın çalışma süreleri ve doğrusal fonksiyonun doğrusal olmayan fonksiyona göre azalma oranları (Bu bulgular 30 koşmanın ortalamasıdır.)

\begin{tabular}{c|c|c|c|c}
\hline \multirow{2}{*}{} & \multicolumn{2}{|c|}{ Ortam 1 } & \multicolumn{2}{c}{ Ortam 2 } \\
\cline { 2 - 5 } & $\begin{array}{c}\text { En Kısa Mesafe } \\
(\mathbf{c m})\end{array}$ & $\begin{array}{c}\text { Çalışma Süresi } \\
(\mathbf{s n})\end{array}$ & $\begin{array}{c}\text { En Kısa Mesafe } \\
(\mathbf{c m})\end{array}$ & $\begin{array}{c}\text { Çalışma Süresi } \\
(\mathbf{s n})\end{array}$ \\
\hline Doğrusal olmayan amaç fonksiyonu & 16,0859 & 6,4720 & 15,4002 & 13,5104 \\
\hline Doğrusal amaç fonksiyonu & 15,7853 & 5,3828 & 14,8258 & 12,5183 \\
\hline Azalma oranı (\%) & 1,87 & 16,83 & 3,73 & 7,34 \\
\hline
\end{tabular}

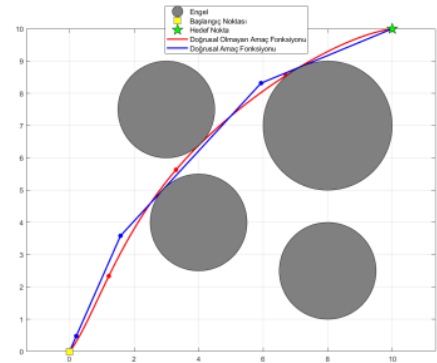

(a)

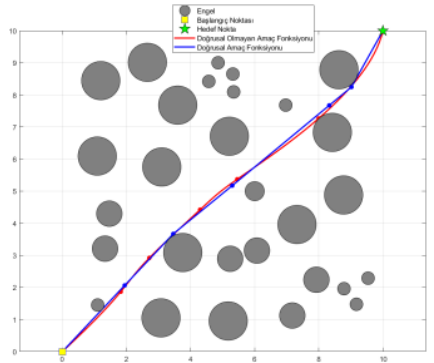

(b)
Şekil 3. Örnek bir çalışma için her iki ortamda elde edilen yollar: (a) Ortam 1, (b) Ortam 2.

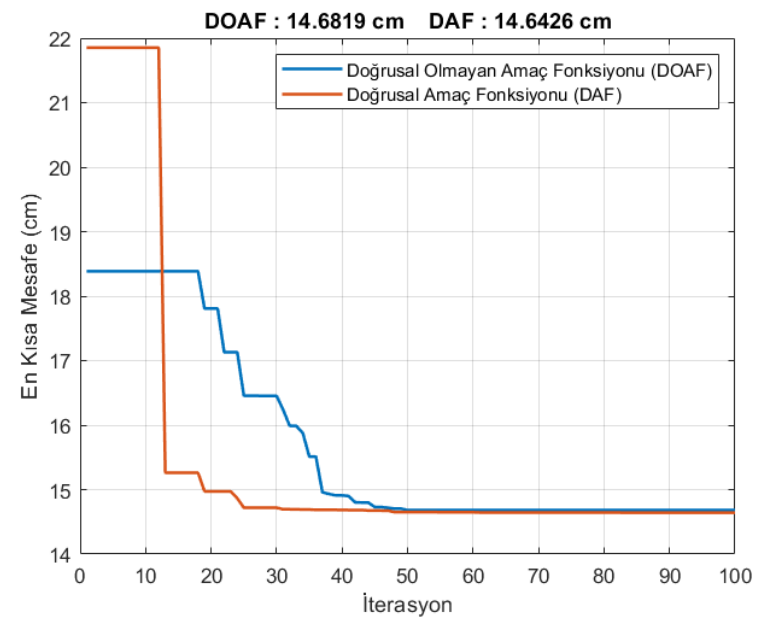

(a)

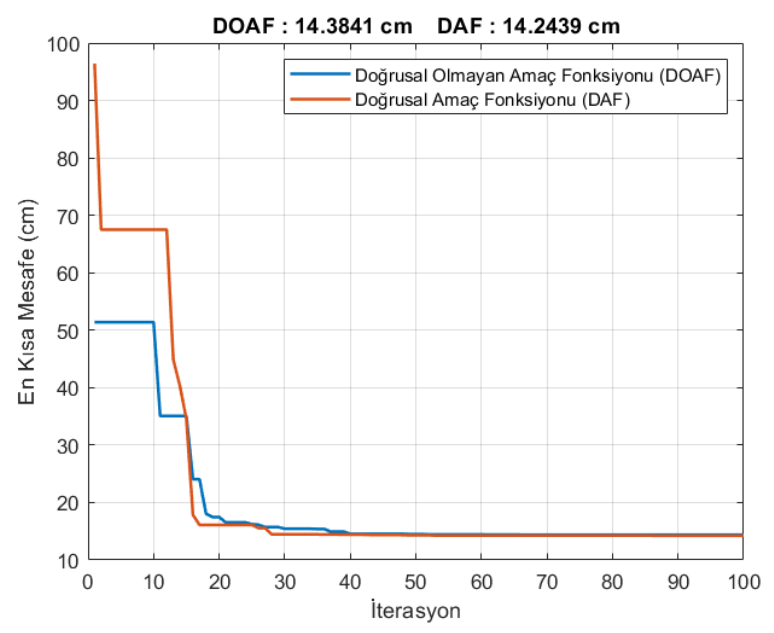

(b)

Şekil 4. Örnek çalışma için her iki ortamda elde edilen yakınsama grafikleri: (a) Ortam 1, (b) Ortam 2.
Tablo 1 genel olarak incelendiğinde, her iki ortam için de doğrusal amaç fonksiyonu ile elde edilen en kısa mesafeler ve algoritma çalışma sürelerinde doğrusal olmayan amaç fonksiyonuna göre bir azalma görülmektedir. Azalma oranları dikkate alındığında, en kısa mesafeler açısından ortam 1'deki oranın ortam 2'ye göre daha düşük seviyelerde olduğu söylenebilir. Çünkü her iki amaç fonksiyonu da kolay problemleri yüksek performansla çözebilir, bu yüzden birbirine yakın sonuçların elde edilmesi kaçınılmazdır. Ancak problem zorlaştıkça doğrusal amaç fonksiyonun bu farkı artırdığ görülmektedir. Algoritma çalışma süreleri açısından, ortam 2'deki oranın ortam 1'e göre daha düşük seviyelerde olduğu görülmektedir. $\mathrm{Bu}$ azalma oranlarındaki düşüş problemin zorlaşmasından kaynaklanmaktadır, ancak yine de her iki ortamda doğrusal amaç fonksiyonun daha hızlı çalıştığı söylenebilir. Şekil 4'teki yakınsama grafikleri ele alındığında, ortam 1'de doğrusal amaç fonksiyonun ortam 2'ye göre daha hızlı yakınsadığı, problem zorlaştıkça bu yakınsama hızında bir düşüş olduğu görülmektedir. Ancak her iki ortam için de doğrusal amaç fonksiyonu ile elde edilen maliyetin daha az olduğu söylenebilir. Genel olarak bu iki fonksiyon en kısa mesafeler, algoritma çalışma süreleri ve problemin zorluğu açılarından değerlendirildiğinde doğrusal amaç fonksiyonunun yol planlama problemini daha az maliyetle çözdüğü sonucuna varılmıştır.

\section{Sonuç}

$\mathrm{Bu}$ çalışmada, mobil robotların yol planlamasında doğrusallığının incelenmesi amaçlanmıştır. Bunun için doğru ve eğri uydurma tabanlı oluşturulan amaç fonksiyonları GA kullanılarak optimize edilmiştir. Farklı zorluk derecelerine sahip ortamlardan elde edilen sonuçlar, doğrusal amaç fonksiyonu ile elde edilen yolların doğrusal olmayan amaç fonksiyonuna göre daha kısa olduğu ve daha hızlı sonuç ürettiğini göstermiştir. Bu sebeple mobil robotların küresel yol planlamasında doğrusal amaç fonksiyonunun kullanılması hem en kısa mesafe hem de algoritma çalışma süresi açısından avantajlı olduğu söylenebilir.

Sonraki çalışmalarda, GA yerine diğer evrimsel veya sürü tabanlı algoritmalar tercih edilerek GA ile karşılaştırılabilir. Ortam ve engel karakteristikleri (engellerin şekli, boyutu, sayısı vb.) değiştirilerek amaç fonksiyonlarının performansları değerlendirilebilir

\section{Kaynakça}

Ajeil, F. H., Ibraheem, I. K., Sahib, M. A., \& Humaidi, A. J. (2020). Multi-objective path planning of an autonomous mobile robot using hybrid PSO-MFB optimization 
algorithm. Applied Soft Computing Journal, 89, 106076. https://doi.org/10.1016/j.asoc.2020.106076

Bakdi, A., Hentout, A., Boutami, H., Maoudj, A., Hachour, O., \& Bouzouia, B. (2017). Optimal path planning and execution for mobile robots using genetic algorithm and adaptive fuzzy-logic control. Robotics and Autonomous Systems, 89, 95-109. https://doi.org/10.1016/j.robot.2016.12.008

CAI, Z., YU, L., XIAO, C., \& LIU, L. (2008). Path Planning for Mobile Robots in Irregular Environment Using Immune Evolutionary Algorithm. In IFAC Proceedings Volumes (Vol. 41, Issue 2). IFAC. https://doi.org/10.3182/200807065-kr-1001.00395

Chołodowicz, E., \& Figurowski, D. (2017). Mobile Robot Path Planning with Obstacle Avoidance using Particle Swarm Optimization. Pomiary Automatyka Robotyka, 21(3), 59-68. https://doi.org/10.14313/par_225/59

Contreras-Cruz, M. A., Ayala-Ramirez, V., \& HernandezBelmonte, U. H. (2015). Mobile robot path planning using artificial bee colony and evolutionary programming. Applied Soft Computing, 30, 319-328. https://doi.org/10.1016/j.asoc.2015.01.067

Davoodi, M., Panahi, F., Mohades, A., \& Hashemi, S. N. (2015). Clear and smooth path planning. Applied Soft Computing Journal, 32 ,

$568-579$. https://doi.org/10.1016/j.asoc.2015.04.017

Elhoseny, M., Tharwat, A., \& Hassanien, A. E. (2018). Bezier Curve Based Path Planning in a Dynamic Field using Modified Genetic Algorithm. Journal of Computational Science, 25, 339-350. https://doi.org/10.1016/j.jocs.2017.08.004

Ergezer, H., \& Leblebicioğlu, K. (2011). Planning unmanned aerial vehicle's path for maximum information collection using evolutionary algorithms. IFAC Proceedings Volumes (IFAC-PapersOnline), 44(1 PART 1), 5591-5596. https://doi.org/10.3182/20110828-6-IT-1002.02977

Heris M. K. (2020). Practical Genetic Algorithms in Python and MATLAB - Video Tutorial (URL: https://yarpiz.com/632/ypga191215-practical-geneticalgorithms-in-python-and-matlab)

Lamini, C., Benhlima, S., \& Elbekri, A. (2018). Genetic algorithm based approach for autonomous mobile robot path planning. Procedia Computer Science, 127, 180-189. https://doi.org/10.1016/j.procs.2018.01.113

Liu, X., Du, X., Zhang, X., Zhu, Q., \& Guizani, M. (2019). Evolution-algorithm-based unmanned aerial vehicles path planning in complex environment. Computers and Electrical Engineering, 80 ,

106493. https://doi.org/10.1016/j.compeleceng.2019.106493

MahmoudZadeh, S., Yazdani, A. M., Sammut, K., \& Powers, D. M. W. (2018). Online path planning for AUV rendezvous in dynamic cluttered undersea environment using evolutionary algorithms. Applied Soft Computing Journal, 70, 929-945. https://doi.org/10.1016/j.asoc.2017.10.025

Mohanta, J. C., Parhi, D. R., \& Patel, S. K. (2011). Path planning strategy for autonomous mobile robot navigation using Petri-GA optimisation. Computers and Electrical Engineering, 37(6), 1058-1070. https://doi.org/10.1016/j.compeleceng.2011.07.007

Niu, H., Ji, Z., Savvaris, A., \& Tsourdos, A. (2020). Energy efficient path planning for Unmanned Surface Vehicle in spatially-temporally variant environment. Ocean Engineering, 196(April 2019). https://doi.org/10.1016/j.oceaneng.2019.106766
Orozco-Rosas, U., Montiel, O., \& Sepúlveda, R. (2019). Mobile robot path planning using membrane evolutionary artificial potential field. Applied Soft Computing Journal, 77, 236251. https://doi.org/10.1016/j.asoc.2019.01.036

Patle, B. K., Parhi, D. R. K., Jagadeesh, A., \& Kashyap, S. K. (2018). Matrix-Binary Codes based Genetic Algorithm for path planning of mobile robot. Computers and Electrical Engineering, 67, 708-728. https://doi.org/10.1016/j.compeleceng.2017.12.011

Qu, H., Xing, K., \& Alexander, T. (2013). An improved genetic algorithm with co-evolutionary strategy for global path planning of multiple mobile robots. Neurocomputing, 120, 509-517. https://doi.org/10.1016/j.neucom.2013.04.020

Raja, R., Dutta, A., \& Venkatesh, K. S. (2015). New potential field method for rough terrain path planning using genetic algorithm for a 6-wheel rover. Robotics and Autonomous Systems, 72 , 295-306. https://doi.org/10.1016/j.robot.2015.06.002

Saicharan, B., Tiwari, R., \& Roberts, N. (2017). Multi Objective optimization based Path Planning in robotics using nature inspired algorithms: A survey. 1st IEEE International Conference on Power Electronics, Intelligent Control and Energy Systems, ICPEICES 2016. https://doi.org/10.1109/ICPEICES.2016.7853442

Sarkar, R., Barman, D., \& Chowdhury, N. (2020). Domain knowledge based genetic algorithms for mobile robot path planning having single and multiple targets. Journal of King Saud University - Computer and Information Sciences, xxxx. https://doi.org/10.1016/j.jksuci.2020.10.010

Song, B., Wang, Z., \& Zou, L. (2021). An improved PSO algorithm for smooth path planning of mobile robots using continuous high-degree Bezier curve. Applied Soft Computing, $100,106960$. https://doi.org/10.1016/j.asoc.2020.106960

Tuncer, A., \& Yildirim, M. (2012). Dynamic path planning of mobile robots with improved genetic algorithm. Computers and Electrical Engineering, 38(6), 1564-1572. https://doi.org/10.1016/j.compeleceng.2012.06.016

Yu, X., Li, C., \& Yen, G. G. (2021). A knee-guided differential evolution algorithm for unmanned aerial vehicle path planning in disaster management. Applied Soft Computing, 98, 106857. https://doi.org/10.1016/j.asoc.2020.106857

Yu, X., Li, C., \& Zhou, J. F. (2020). A constrained differential evolution algorithm to solve UAV path planning in disaster scenarios. Knowledge-Based Systems, 204, 106209. https://doi.org/10.1016/j.knosys.2020.106209 